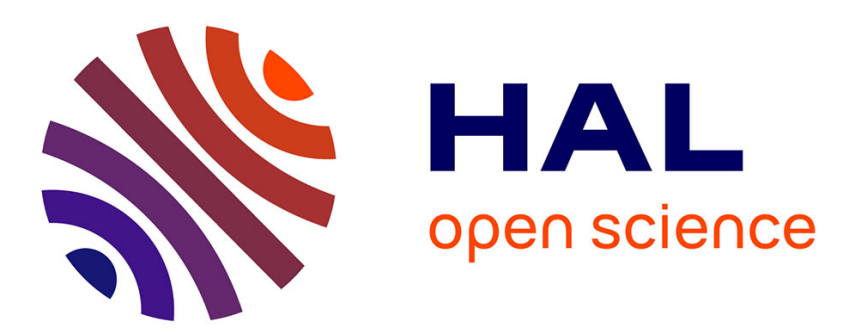

\title{
An evaluation of constitutive relations for high-rate material behaviour using the tensile Hopkinson-bar
}

\author{
J. Noble, J. Harding
}

\section{To cite this version:}

J. Noble, J. Harding. An evaluation of constitutive relations for high-rate material behaviour using the tensile Hopkinson-bar. Journal de Physique IV Proceedings, 1994, 04 (C8), pp.C8-477-C8-482. 10.1051/jp4:1994874 . jpa-00253435

\section{HAL Id: jpa-00253435 https://hal.science/jpa-00253435}

Submitted on 1 Jan 1994

HAL is a multi-disciplinary open access archive for the deposit and dissemination of scientific research documents, whether they are published or not. The documents may come from teaching and research institutions in France or abroad, or from public or private research centers.
L'archive ouverte pluridisciplinaire HAL, est destinée au dépôt et à la diffusion de documents scientifiques de niveau recherche, publiés ou non, émanant des établissements d'enseignement et de recherche français ou étrangers, des laboratoires publics ou privés. 


\title{
An evaluation of constitutive relations for high-rate material behaviour using the tensile Hopkinson-bar
}

\author{
J.P. Noble and J. Harding \\ Department of Engineering Science, University of Oxford, Parks Road, Oxford OX1 3PJ, U.K.
}

\begin{abstract}
Tensile tests have been performed on specimens of Remco iron at strain rates from quasistatic to $-2500 / \mathrm{s}$ and high-speed photography has been used to monitor the deformation of the specimen in tests at the highest rates. The DYNA 2D finite element code and the Johnson-Cook and Zerilli-Armstrong constitutive relations have been used to model the specimen behaviour in the impact test and the numerical predictions are compared with experimental measurements.
\end{abstract}

\section{INTRODUCTION}

Situations frequently arise, for example in bird impact on aero engine fan blades, where the engineer is required to predict the extent of the resulting damage should such an impact occur. Advances in computers and computing techniques have made such predictions a possibility provided sufficient information is available on the mechanical behaviour of the materials involved at the very high rates of strain likely to be imposed. Such information is required in the form of a constitutive equation which relates the stress system in the material to the instantaneous values of strain, strain rate and temperature. While strain is not a true state function, constitutive equations of this form usually allow an adequate description of the structural response to be predicted for most engineering purposes. When incorporated in a suitable finite element code, for example DYNA 2D, the constitutive equation allows the changing deformation and stress state within the component to be determined during the course of the impact for the given boundary and loading conditions.

To obtain the appropriate constitutive equation for a given material, data are usually obtained from standard specimen tests which are assumed to be performed at constant temperature, that of the medium surrounding the specimen during the test, and strain rate, given by the applied extension rate. In practice, however, these assumptions are almost always invalid, particularly at high rates of strain where, because of the very short times involved, an adiabatic rise in temperature due to the heat generated by plastic work may be expected. Depending both on the type of specimen being tested and on the work-hardening response of 
the test material and its dependence on strain rate, the extent of uniform deformation in the standard specimen test may be severely limited and further problems arise because of the localisation of plastic flow leading to wide variations in strain rate within the test specimen.

In an earlier study of the double-notch-shear test [1], a test specifically developed in order to test materials at the highest strain rates, doubts about the validity of the assumptions regarding uniformity of deformation were confirmed. Nevertheless, by using high-speed photography to monitor the deformation of the specimen during the course of the impact and the Hopkinson-bar technique to determine the applied loads and the corresponding externally imposed deformation rate, it was possible to distinguish between different constitutive relations for the test material. While a rate-independent equation was capable of predicting the deformed shape of the specimen during the impact process, a rate-dependent equation was needed if the required loads were also to be predicted with reasonable accuracy.

In the present investigation the same approach has been applied to the study of the tensile split Hopkinsonbar test. High-speed photography has been used to monitor the onset and development of localised deformation in the necked region and the maximum reduction in area determined at each stage of the test. The experimental results obtained are compared with numerical predictions using DYNA 2D and either the Johnson-Cook or the Zerilli-Armstrong forms of constitutive relation. Better agreement is obtained when the Zerilli-Armstrong relation is used.

\section{EXPERIMENTAL DETAILS}

\subsection{Experimental Techniques}

The test material was a low carbon $(<0.02 \%)$, fine-grain size (20 $\mu$ m grain diameter), high-ductility Remco iron. Standard cylindrical tensile specimens of this material were tested at a quasi-static, an intermediate and an impact strain rate, the impact tests being performed in a split Hopkinson-bar apparatus at a mean rate of about $2500 / \mathrm{s}$. In some of the impact tests the changing specimen dimensions during the course of the impact were monitored by high-speed photography, using a Cordin 377 rotating-mirror spinning-drum camera, capable of recording up to 500 frames at framing intervals as low as $5 \mu \mathrm{s}$ [2].

\subsection{Experimental Results}

Mean nominal stress-nominal strain curves for the three rates of strain, derived from several tests at each rate, are shown in fig. 1 . Several frames from a set of photographs for one of the impact tests are shown in fig. 2. Frame 15 corresponds to the start of the test and successively numbered frames are at $10 \mu$ s intervals. The first signs of necking (or waisting) in the specimen are seen in frame 22, where the nominal strain (percentage elongation) was $13.6 \%$, beyond the point of maximum load on the impact stress-strain curve of fig. 1 but still a very low value of strain for that at the limit of uniform deformation. The increasing reduction in area at the neck during the course of the test as measured from the photographs of fig. 2 is shown in fig. 3, upper and lower bounds on this measurement being given.

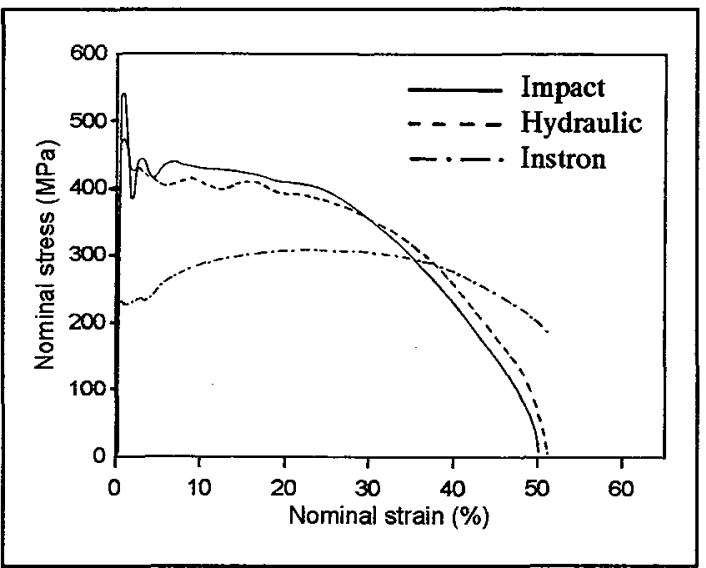

Fig. 1 Effect of Strain Rate on Nominal StressStrain Curves for Remco Iron 


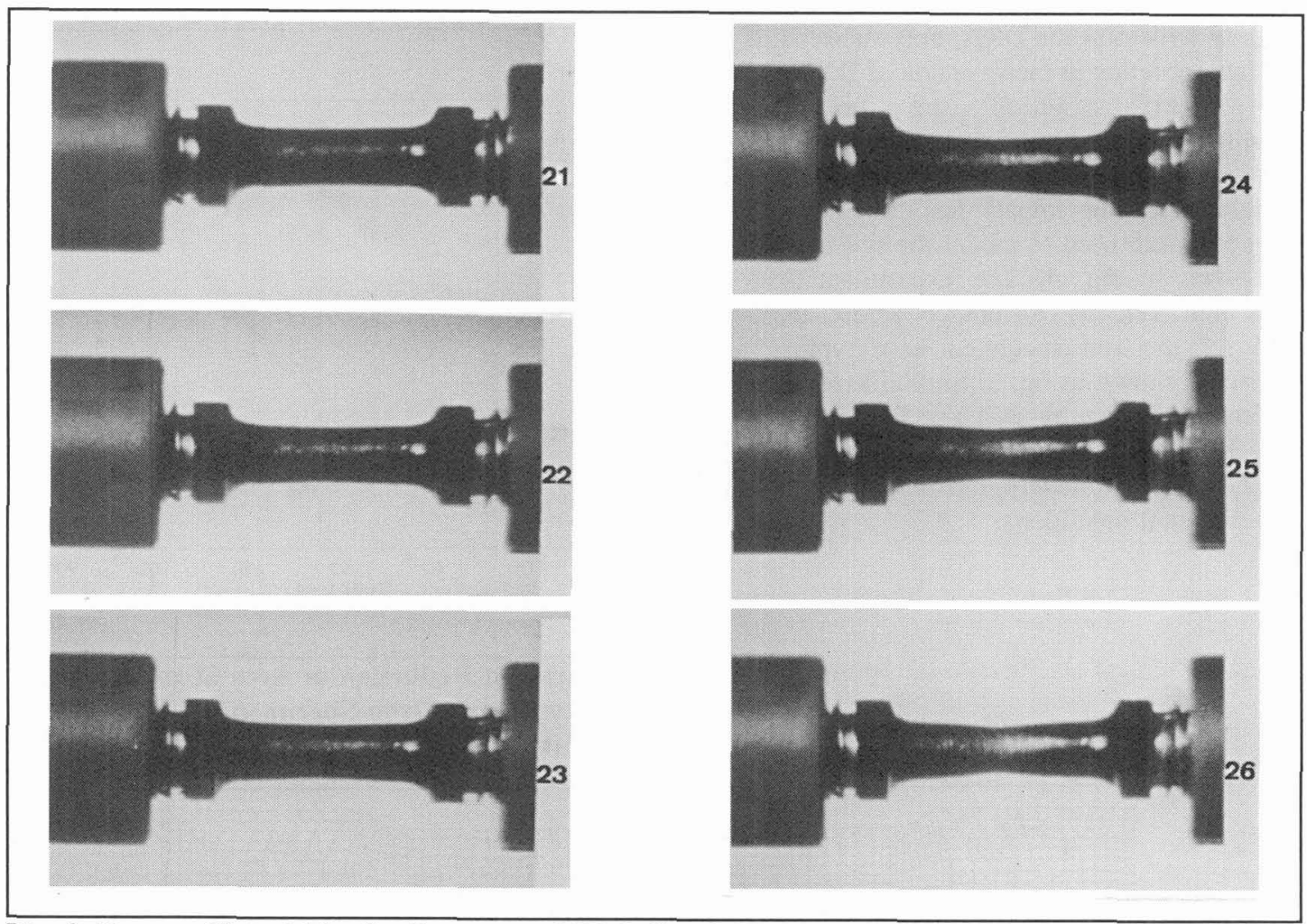

Fig. 2 Frames 21 to 26 in the Sequence of High-Speed Photographs for an Impact Test on Remco Iron

\section{NUMERICAL MODELLING}

\subsection{Constitutive Relations}

Two constitutive relations are used in the numerical modelling of the tensile impact test, the original Johnson-Cook relation [3],

$$
\sigma_{y}=\left[A+B \varepsilon^{n}\right]\left[1+C \ln \dot{\varepsilon}^{*}\right]\left[1-T^{* m}\right]
$$

using their values for the material constants, and the Zerilli-Armstrong relation in the form proposed for bcc materials [4], modified to include a temperature dependence of the strain hardening term,

$$
\begin{aligned}
\sigma_{y}= & \Delta \sigma_{G^{\prime}}+k_{g} l_{g d}^{-1 / 2}+C_{1} \exp \left(-C_{3} T+C_{4} T \ln \left(\dot{\boldsymbol{\varepsilon}} / \dot{\boldsymbol{\varepsilon}}_{o}\right)\right) \\
& +(s m 1-\operatorname{sm} 2 T) C_{5} \varepsilon^{n}
\end{aligned}
$$

using material constants derived from experimental data such as that given in fig. 1 obtained both at Oxford and at DRA, Fort Halstead.

\subsection{Finite Element Method}

The DYNA 2D finite element code was used to model the tensile impact test. This is an explicit code which is widely used for studying problems involving high strain rates. The Johnson-Cook constitutive relation was already incorporated in the available version of DYNA 2D. This was not the case for the Zerilli-Armstrong relation so a specific sub-routine had to be written. This followed quite closely that 
already written at the DRA, Fort Halstead, for incorporation in their version of DYNA 2D, against which the present modifications were validated by comparing the predictions of the two codes for a simulated Taylor impact test. The finite element mesh used to model the specimen is shown in fig. 4. The experimentally measured velocity difference across the ends of the test specimen in a typical impact is shown in fig. 5 . Similar velocity differences, given by $\mathrm{BC} 1$ and $\mathrm{BC} 2$ in fig. 5 were applied in the numerical analysis. $\mathrm{BC} 2$ more closely reflected the experimental conditions.

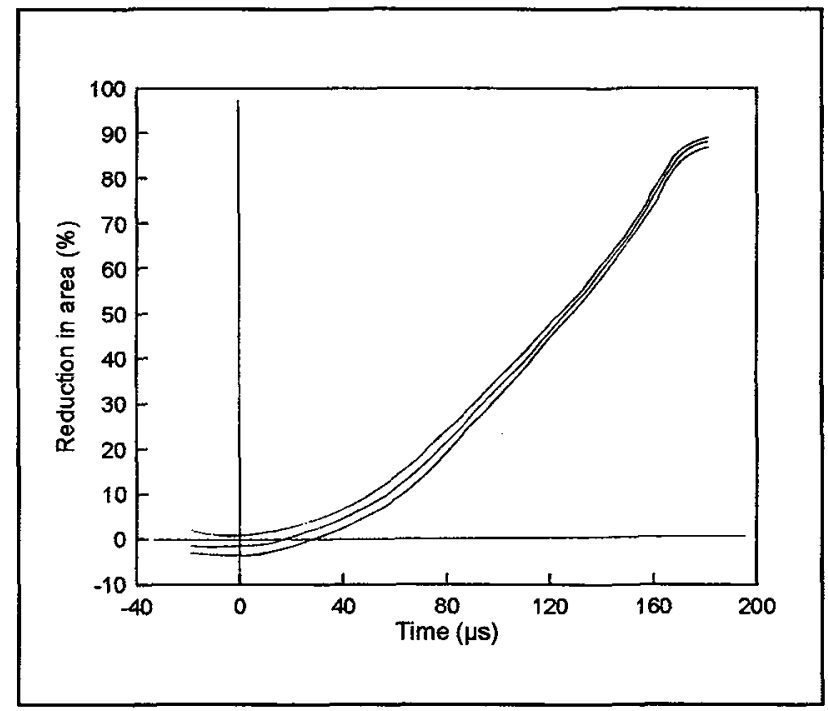

Fig. 3 Variation of Reduction in Area at the Neck for Impact Test on Remco Iron Specimen

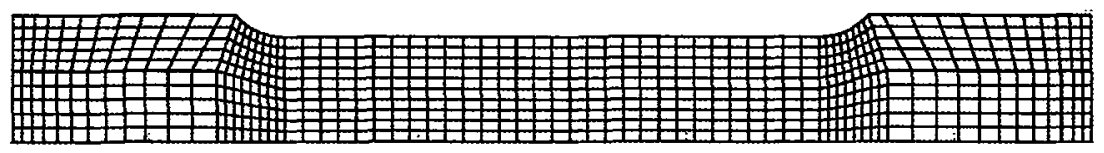

Fig. 4 Finite Element Mesh for Tensile Specimen

\subsection{Results of Numerical Analysis}

Predicted loading histories using both the Johnson-Cook and the ZerilliArmstrong constitutive relations and the two boundary conditions are compared in fig. 6. The choice of boundary condition has little effect on the load at any given nominal strain but the slightly higher velocities assumed by boundary condition $\mathrm{BC} 2$ lead to higher values of nominal strain at any given time in the analysis. A distinct difference is apparent, however, between the general shapes of the loading histories predicted by the two constitutive relations, the ZerilliArmstrong relation predicting significantly higher loads at the start of the deformation process and a much greater degree of work-softening as deformation proceeds.

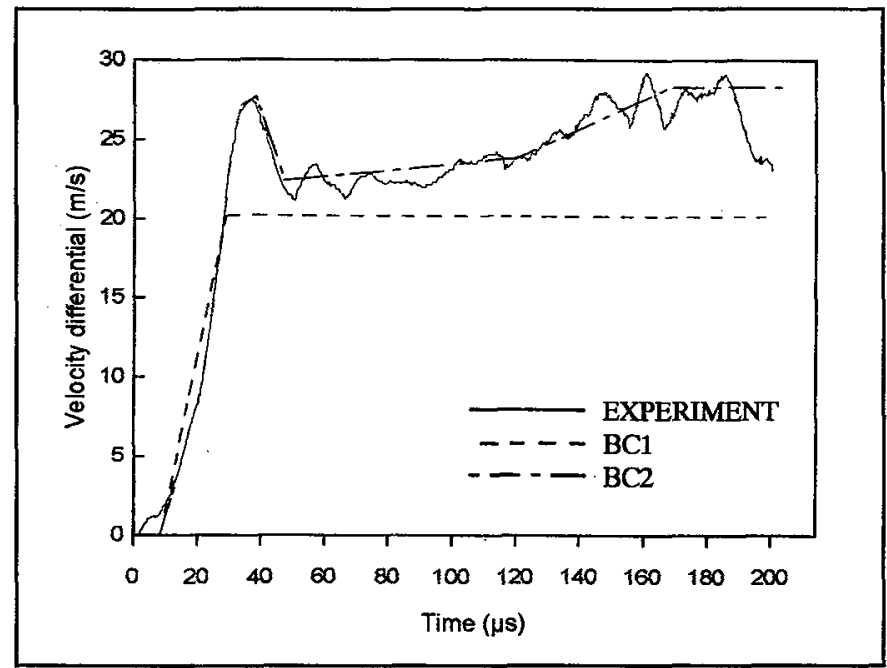

Fig. 5 Comparison of Boundary Conditions for Numerical Analysis with Experimentally Measured Behaviour 
A significant difference is also apparent between the predictions for the maximum reduction in area given by the two constitutive relations as shown in fig. 7. Again the only effect of using boundary condition $\mathrm{BC} 2$ is to cause a greater reduction in area at any given time in the analysis.

\section{DISCUSSION}

A comparison between the experimentally determined and the numerically predicted time dependence of the maximum reduction in area during the impact test is given in fig. 8. The Johnson-Cook relation significantly underestimates the reduction in area but very good agreement is obtained when the ZerilliArmstrong relation is used. This difference may arise, in part, because the material constants in the ZerilliArmstrong relation were determined specifically for the material tested here whereas in the Johnson-Cook relation their original material constants were used. A more significant difference between the two constitutive relations, however, lies in the way they account for the effect of temperature. The greater reduction in area predicted by the Zerilli-Armstrong relation is consistent with the greater work-softening which it also predicts in the loading history, as shown in fig. 6 . This predicted loading history is also closer, in general form, than that obtained using Johnson-Cook, to the experimentally observed loading history, as shown in fig. 9. However fig. 9 also shows that Zerilli-Armstrong significantly overestimates the actual loads at any given time during the deformation process. Previous work [1] has shown that the ability to accurately predict force, rather than deformed shape, is a more demanding test of the validity of a constitutive relation. This discrepancy may, therefore, be an indication that there are still limitations to the Zerilli-Armstrong relation in its current form. However, there is some evidence that this discrepancy may indicate an error in the implementation of the Zerilli-Armstrong relation in the DYNA 2D code. Checks on the validity of this implementation were in terms of the Taylor impact test where it is not possible in the experimental set-up to determine forces. A further check on this implementation is required, therefore, before a firm conclusion can be drawn.

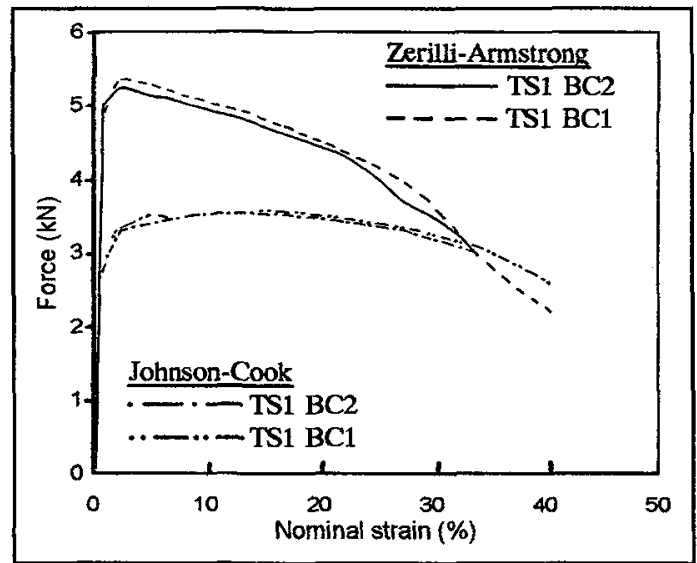

Fig. 6 Effect of Boundary Condition and Constitutive Relation on Predicted Loading History

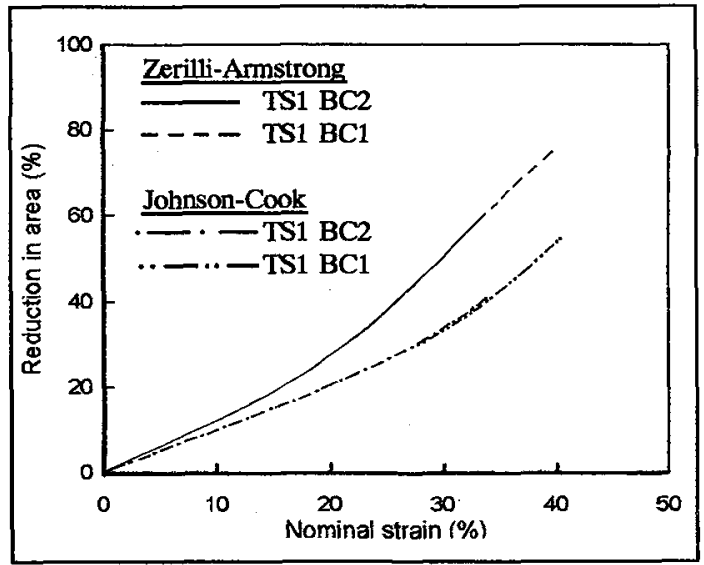

Fig. 7 Effect of Boundary Condition and Constitutive Relation on Predicted Maximum Reduction in Area

\section{CONCLUSIONS}

Tensile tests on Remco iron specimens have been performed over a range of strain rate from quasi-static to impact. High-speed photography has been used to monitor the deformation in the impact tests. Both the Johnson-Cook and the Zerilli-Armstrong constitutive relations have been used in the finite element code DYNA 2D to model the observed experimental response. In general significantly better agreement is obtained when the Zerilli-Armstrong relation is used. A discrepancy between the predicted and 


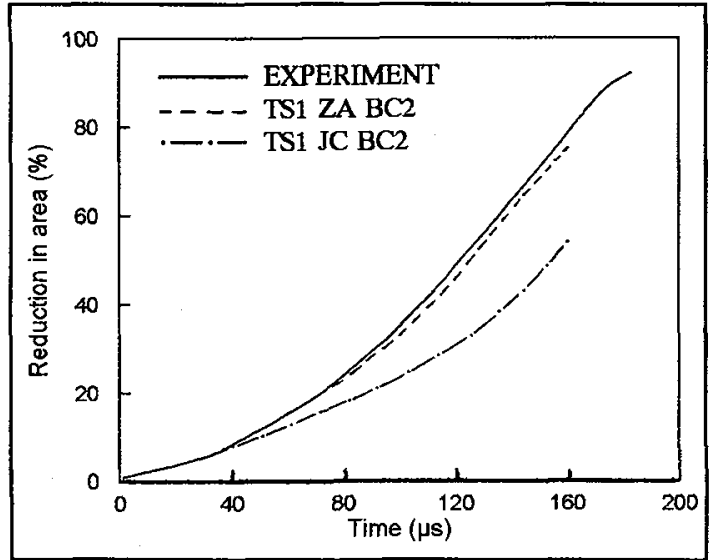

Fig. 8 Comparison between Predicted and Experimentally Measured Maximum Reduction in Area

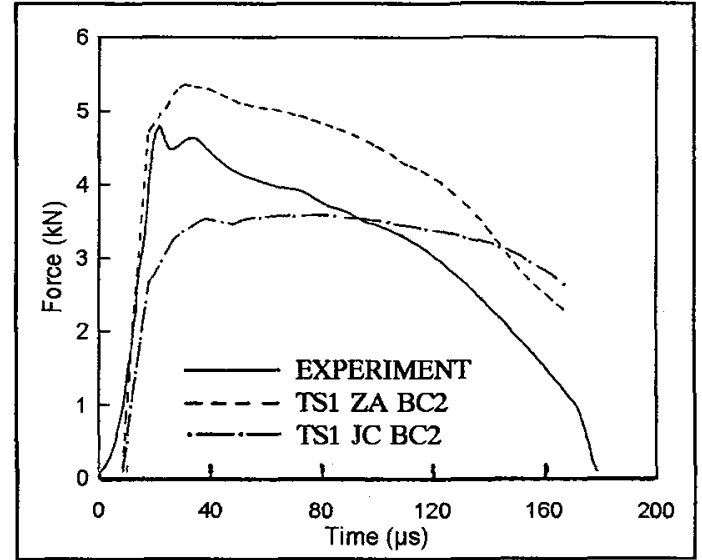

Fig. 9 Comparison between Predicted and Experimentally Measured Loading Histories

experimentally measured forces was obtained but may be due to an error in the implementation of the Zerilli-Armstrong relation in the DYNA 2D code.

\section{REFERENCES}

1. D. J. Ruiz, J. Harding and C. Ruiz, High Strain Rate Testing of Materials - A Fully Validated Test Calibration by a Hybrid Numerical/Experimental Technique, in Proc. DYMAT 91, J. de Physique IV Colloque No. 3, Suppl. au J. de Phys. III, 1991, Vol. 1, Octobre, pp. C3/465-C3/470.

2. J. P. Noble, The Problems of Synchronizing Strain Gauge and Photographic Data for the Tensile Hopkinson-bar Test, Interim Report on Agreement No. D/ER1/9/4/2057/128, Oxford University Engineering Department, Solid Mechanics Group Report No. JPN/009, December 1991.

3. Johnson G.R., Cook W. H., A constitutive model and data for metals subjected to large strains, high strain rates and high temperatures, Proc. 7 th Int. Symposium on Ballistics, The Hague, The Netherlands, April 1983, pp. 541-547.

4. Zerilli F.J., Armstrong R.W., Dislocations mechanics based constitutive relations for material dynamics calculations, J. Appl. Phys., Vol. 61, No. 5, 1987, p. 1816. 